\title{
Dry Sliding Wear Behavior of Ti6Al4V and TaN against TiN Deposited Steel Surface
}

\author{
A. Elaya Perumal, I. Saravanan \\ Department of Mechanical Engineering, CEG Anna University, Chennai, India \\ Email: ep mal@yahoo.com, is.annauniv@gmail.com
}

Received 11 May 2015; accepted 23 July 2015; published 30 July 2015

\begin{abstract}
The objective of this research is to study the dry sliding wear behaviour of metal surfaces and influences of their surface hardness. The improved hardness of the TiN deposited surface was about $1763 \mathrm{Hv}$. The worn surface Scanning Electron Microscope (SEM) morphology exhibits the surface damage due to varying wear test parameters. The Electron Dispersive Spectroscopy (EDS) reveals that the material transfer between the counter parts and the wear mechanism has been involved. The minimum specific wear rate of TiN surface was $0.0018 \mathrm{mg} / \mathrm{Nm}$ and $0.0026 \mathrm{mg} / \mathrm{Nm}$ against Ti6Al4V alloy and TaN respectively.
\end{abstract}

\section{Keywords}

TiN, Ti6Al4V, Dry Sliding Wear, TaN

\section{Introduction}

The hard TiN deposition on Stainless Steel type 316L (SS 316L) surface improved their surface hardness and wear properties. The metal to metal contacts in sliding leads for abrasive and adhesive wear and it depends on material properties and wear test parameters. Ti6Al4V is the soft material having hardness about $270 \mathrm{Hv}$ compared to Tantalum nitride (TaN) which is about the hardness of $1700 \mathrm{Hv}$. The surface hardness was taken into account to analyse the wear mechanism which is the major cause for protect the surface from deformation.

TaN has improved high hardness, high melting point and chemical inertness, which make them as protective layer for prospective applications under severe conditions like high temperature or chemically corrosive environments [1] [2]. TaN makes the columnar grain structure, in both amorphous and crystalline films [3], and their wear performance may be compromised because of failure along these grain boundaries. The higher friction coefficient and wear rate of TaN have been restricted their performance in tribology [4].

Ceramic thin solid films, the transition metal nitride compounds, have been used as hard, adhesive, wear resistant coatings. The studies about mechanical and wear behavior of transition metal nitrides are well established [5]-[7]. The nitride coatings improved, the increase of mechanical and tribological properties was obtained, such as TiN, $\mathrm{ZrN}, \mathrm{CrN}[8]$.

The objective of this work is to study the effect of surface hardness in dry sliding wear environment on metallic contact surfaces. The mechanism and the phenomenon are to be analysed well when the soft material sliding 
on the hard surface and vice versa. The effect of wear test parameters and their influences has been carried out for varying loading conditions.

\section{Materials and Methods}

The disc material SS 316L was prepared with the geometry of $60 \mathrm{~mm}$ diameter and $5 \mathrm{~mm}$ thickness. The wear test was carried out for the track diameter of $25 \mathrm{~mm}$. The samples were polished, using diamond paste and the average surface roughness (Ra) of $0.4 \mu \mathrm{m}$ was obtained. TiN is the coating material having a density of 5.22 $\mathrm{g} / \mathrm{cm}^{3}$.

The arc deposition set up for TiN deposition process is shown in Figure 1. The TiN deposition starts with the high current, low voltage arc on the surface of a cathode (Ti) that gives rise to a highly energetic emitting region known as a cathode spot. The temperature at the cathode spot is around $750^{\circ} \mathrm{C}$, which results in a high velocity jet of a vaporized cathode material, leaving a crater behind on the cathode surface. The Nitrogen was passed as reactive gas into the chamber during deposition. At the high temperature, forms titanium nitride and after that no further nitrogen compounds were formed especially in steel surface due to insufficient nitrogen on steel surface. [9].

The $5 \mathrm{~mm}$ in diameter with $22 \mathrm{~mm}$ TaN and Ti6Al4V pins were made as a counterpart of the TiN deposited steel surface, for wear studies as per the ASTM standard G99-05. The effect of load is analyzed by keeping the other controlling parameters as constant i.e., sliding velocity of $0.25 \mathrm{~m} / \mathrm{s}$ for sliding distance of $1500 \mathrm{~m}$.

\section{Characterization}

\subsection{Structural Analysis}

Figure 2(a) shows the SEM morphology of the TiN coated steel surface, which exhibits molten titanium globules called macro droplets emitted from the cathode at high sliding velocity, deposited on the surface, and appear as white and spherical spots. The inhomogeneity of the TiN coated surface is caused by the incident macro droplets [10].

The coating thickness was measured by using the Optical Microscope (OM) image. Figure 2(b) shows the cross sectional OM image taken of the TiN coated SS 316L sample in 400× magnification. From the microscopic image a continuous contrast line can be seen, which indicates the coating thickness influenced by the process

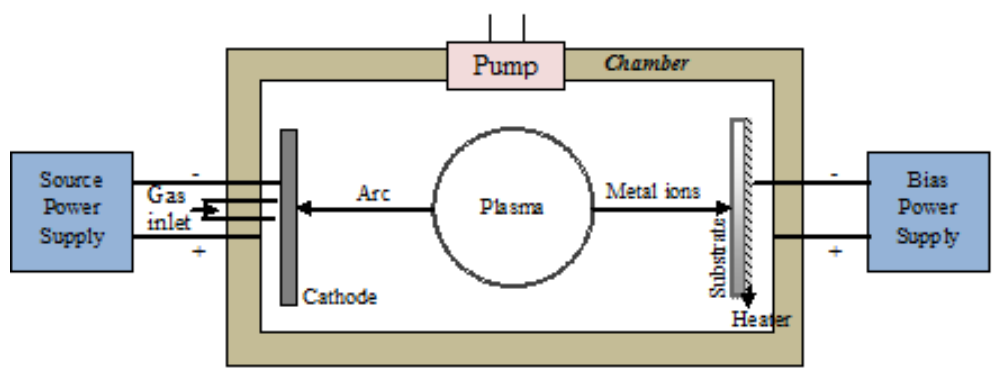

Figure 1. Schematic representation of the cathodic arc deposition.

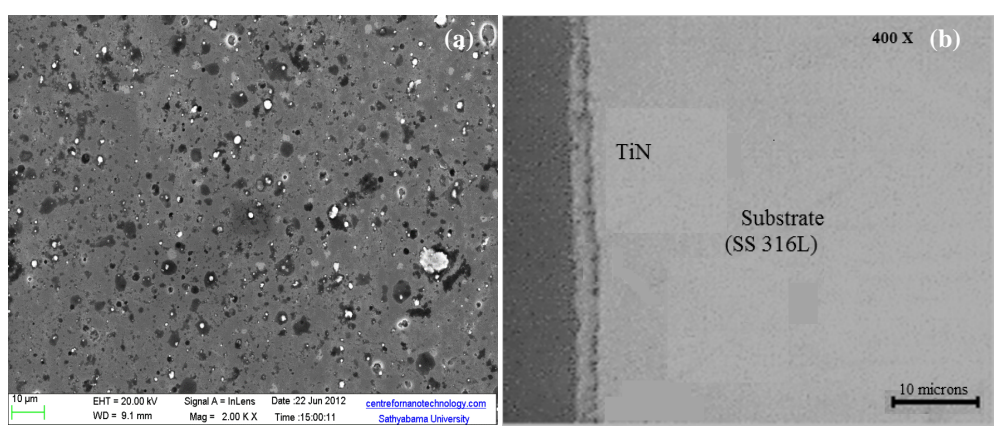

Figure 2. (a) SEM image (b) Coating thickness of TiN coated SS 316L. 
parameter. The coating thickness is also measured with the help of AutoCAD 2010 software as explained in [11]. It confirms that the coating thickness was about $4-6 \mu \mathrm{m}$.

\subsection{Surface Profile}

Figure 3(a) shows the three dimensional surface profile of the TiN-coated SS 316L. The improved hardness of the TiN coated surface is around $1763 \mathrm{Hv}$ for the surface roughness (Ra) of $0.05 \mu \mathrm{m}$ shown in Figure 3(b). The surface roughness is influenced by the substrate temperature and substrate bias [12].

\subsection{X-Ray Diffraction (XRD) Analysis}

The TiN XRD intensity peaks demonstrate the improved crystalline nature which is shown in Figure 4. The XRD pattern of the TiN surface is good agreement with the JCPDS file \#77-1893 and \#87-0633 for strong peak at (111) plane and weak peak at (311) plane respectively [13]. From the observation of the orientation peak, it was noticed that the reflection plane of (220) is stronger compared other peaks which is due to the small radius of curvature at the peak [14]. A peak at $36^{\circ}$ indicates a strong (111) orientation, and the osbornite phase which were predictable for TiN deposition.

\subsection{Micro Hardness}

The micro hardness tests were carried out as per the ASTM: E10 standards, with a load of $0.025 \mathrm{~kg}$, using the micro hardness tester (Wilson Halbert; $0.01-1 \mathrm{~kg}$ ). The micro hardness of the selected materials is shown in Figure 5. The hardness of the TiN coated disc improved nine times compared to uncoated SS 316L due to the hard and dense coating using CAD. The counterparts having the hardness of $273 \mathrm{Hv}$ and $1709 \mathrm{Hv}$ for Ti6Al4V

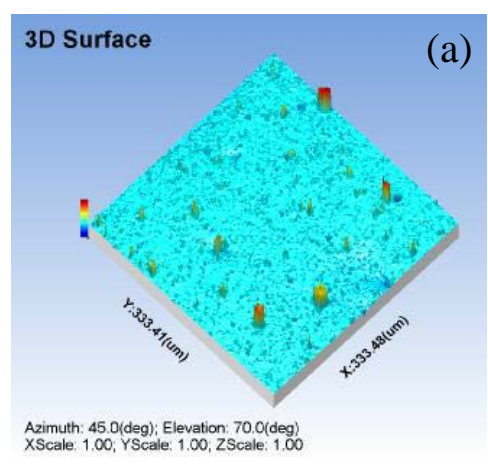

\begin{tabular}{|c|c|c|}
\hline \multicolumn{2}{|c|}{ ISO 4287 } & (b) \\
\hline Amplitude parameters & - Rou \\
\hline Rp & 0.455 & $\mu \mathrm{m}$ \\
\hline Rv & 0.482 & $\mu \mathrm{m}$ \\
\hline $\mathbf{R z}$ & 0.937 & $\mu \mathrm{m}$ \\
\hline $\mathbf{R c}$ & 0.427 & $\mu \mathrm{m}$ \\
\hline $\mathbf{R t}$ & 1.39 & $\mu \mathrm{m}$ \\
\hline Ra & 0.0554 & $\mu \mathrm{m}$ \\
\hline Rq & 0.105 & $\mu \mathrm{m}$ \\
\hline Rsk & 0.613 & \\
\hline Rku & 21.8 & \\
\hline Material & Ratio parameters - F \\
\hline Rmr & 96.5 & $\%$ \\
\hline Rdc & 0.069 & $\mu \mathrm{m}$ \\
\hline
\end{tabular}

Figure 3. (a) 3D-surface profile (b) Measured Parameters of the TiN coated SS 316L.

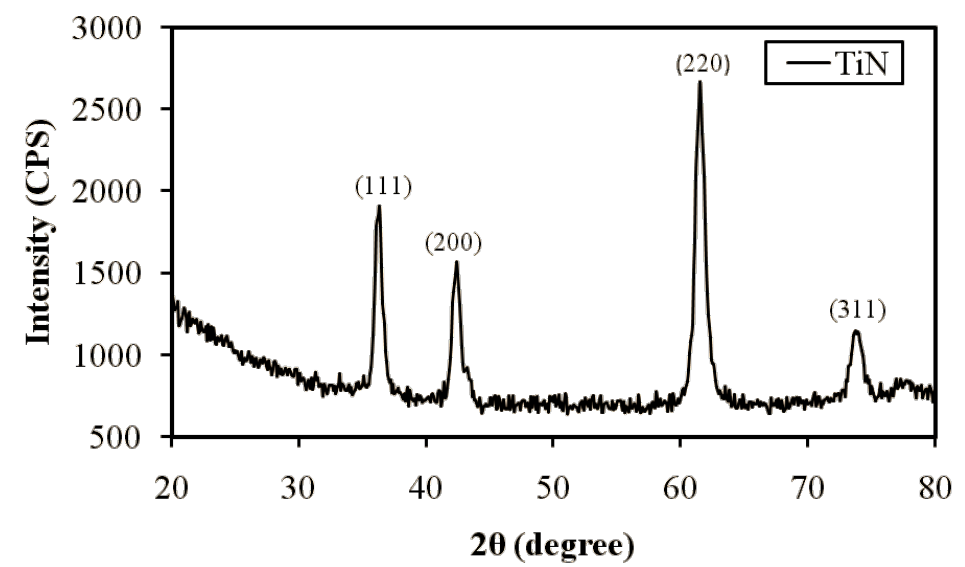

Figure 4. XRD patterns of TiN coated SS 316L. 
alloy and TaN respectively.

\section{Wear Behaviour}

The effects of the load on the specific wear rate for the TiN coated SS 316L against Ti6Al4V alloy and TaN is shown in Figure 6. The specific wear rate of the TiN coated SS 316L increases with increasing the load, but remains lesser against Ti6Al4V alloy compared to TaN. The sliding between two hard materials leads to severe wear and the sliding of soft material on hard material leads to mild wear [15]. The minimum specific wear rate of TiN surface was $0.0018 \mathrm{mg} / \mathrm{Nm}$ and $0.0026 \mathrm{mg} / \mathrm{Nm}$ against Ti6Al4V alloy and TaN respectively.

Figure 7 shows the specific wear rate of Ti6Al4V alloy and TaN against TiN coated SS 316L. The specific wear rate of the counterpart decreases with increasing the load and the minimum specific wear rate obtained about $0.001 \mathrm{mg} / \mathrm{Nm}$ for TaN. The TaN had better wear resistance compared to Ti6Al4V alloy against TiN coated SS 316L due to the oxide tribo layer formation on the sliding surface [16].

The EDS of the TiN coated SS 316L against Ti6Al4V alloy and TaN is shown in Figure 8. Figure 8(a) shows severe loss of materials on the disc surface compared to Figure 8(b) and also it evidences the transfer of counterpart was high with Ti6Al4V alloy. From Figure 9(b), it was conformed that the debris of Ti6Al4V alloy

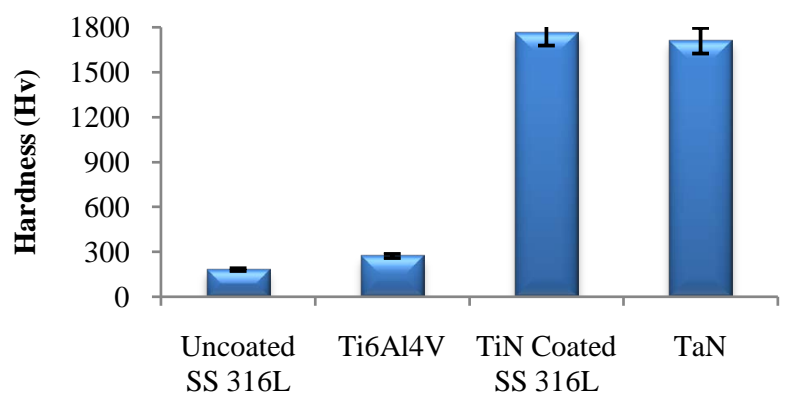

Figure 5. Example of a figure caption (figure caption).

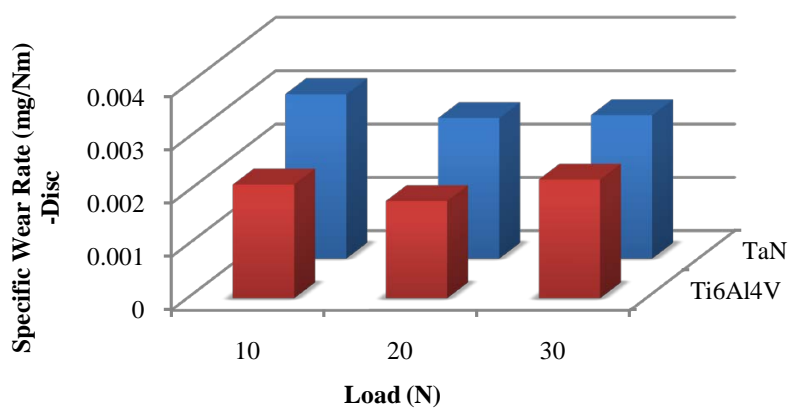

Figure 6. Comparison of specific wear rate for disc.

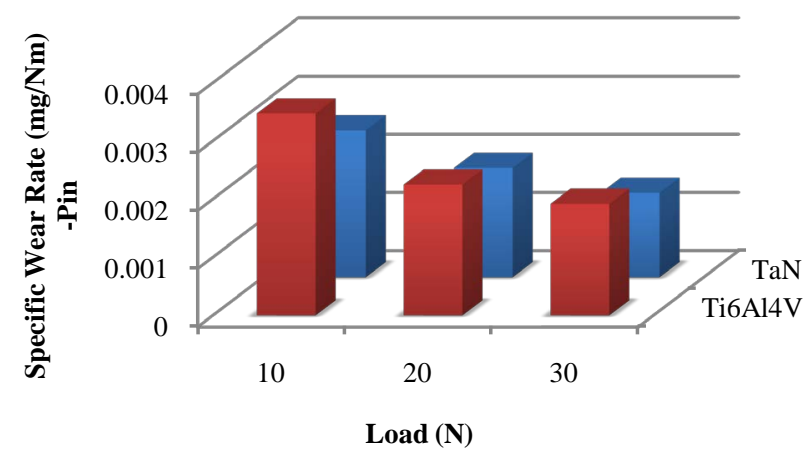

Figure 7. Comparison of specific wear rate for pin. 


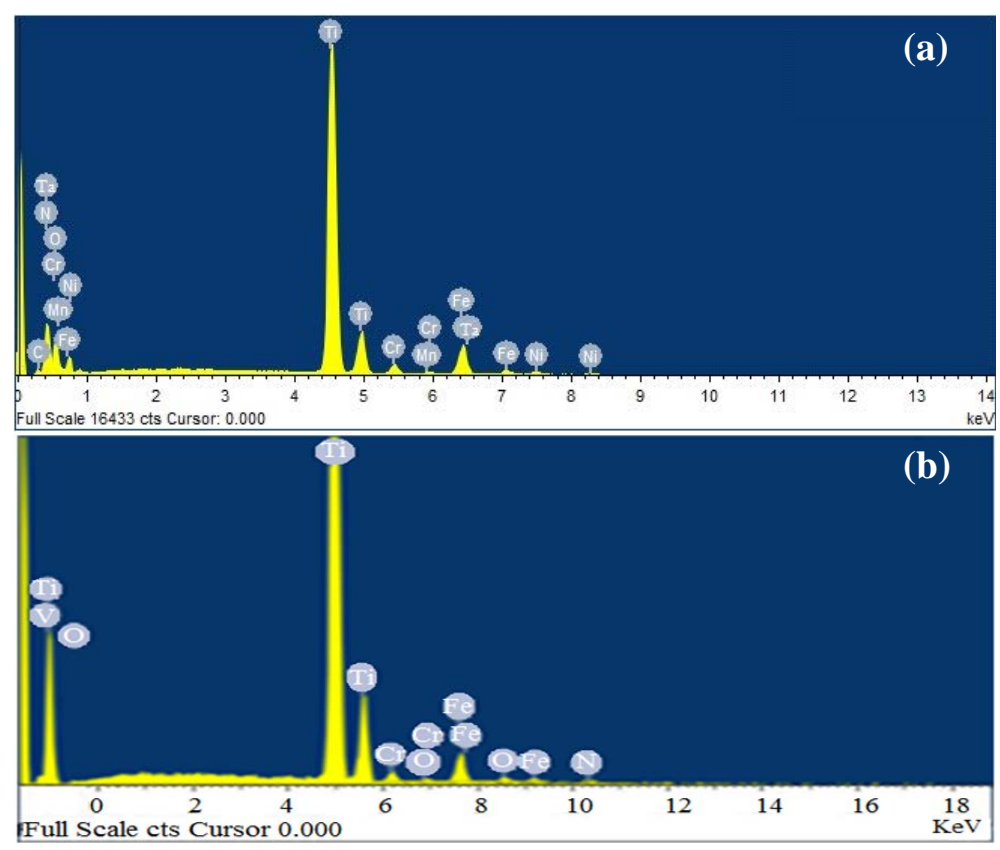

Figure 8. Comparison of EDS for TiN coated disc against (a) Ti6Al4V (b) TaN.

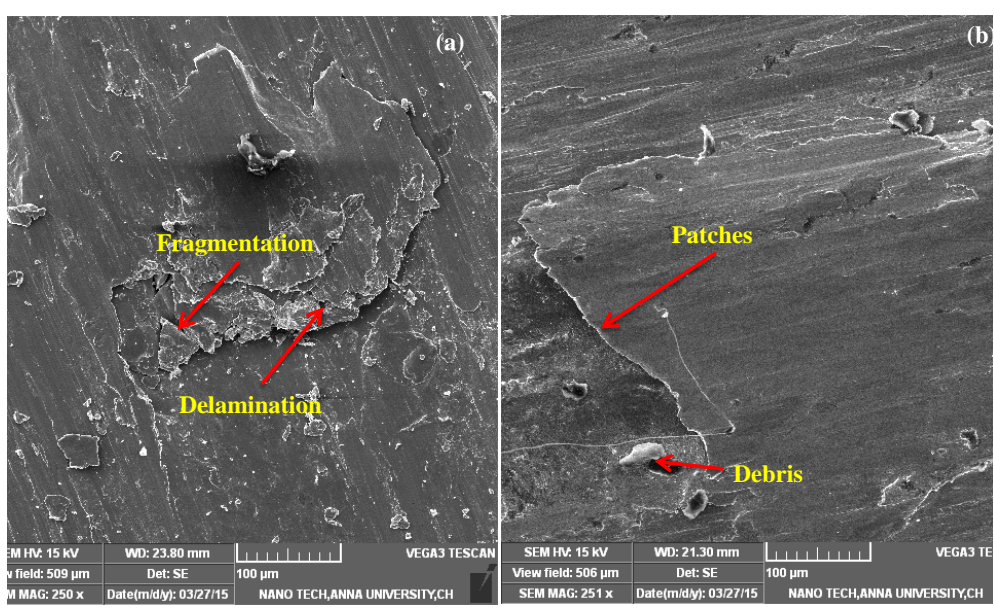

Figure 9. Comparison of SEM for TiN coated disc against (a) Ti6Al4V (b) TaN.

on the disc surface due to adhesive wear mechanism [17]. Figure 9(a) reveals that the disc surface was severely delaminated and fragmented due to the abrasive wear between the hard mating surfaces.

\section{Conclusions}

$>$ The bio-compatible TiN material was coated over SS 316L by Arc Deposition, which improves the surface hardness of the substrate. The coating thickness was measured as about $4-6 \mu \mathrm{m}$ using $\mathrm{OM}$, and its average surface roughness was measured as about $0.05 \mu \mathrm{m}$ using surface profile.

$>$ The crystallography result confirms the Osbornite phase, with a strong orientation of plane (220). This is due the double bent formation of (220). Due to the strong bonding nature of the TiN coated substrate, the micro hardness was increased by about 9 times that of the uncoated substrate.

> The EDS analysis confirms that the material transfer from the counterpart to TiN coated SS 316L disc and the formation of the oxidation layer on the disc, which facilitates to improve the wear resistance of the coated 
disc surface. The SEM morphology indicates the severe worn surface of the TiN coated surface against TaN than Ti6Al4V alloy.

$>$ The minimum specific wear rate of TiN surface was $0.0018 \mathrm{mg} / \mathrm{Nm}$ and $0.0026 \mathrm{mg} / \mathrm{Nm}$ against Ti6Al4V alloy and TaN respectively.

\section{References}

[1] Lemberger, M., Thiemann, S., Baunemann, A., Parala, H., Fischer, R.A., Hinz, J., Bauer, A.J. and Ryssel, H. (2007) MOCVD of Tantalum Nitride Thin Films from TBTEMT Single Source Precursor as Metal Electrodes in CMOS Applications. Surface and Coatings Technology, 201, 9154-9158. http://dx.doi.org/10.1016/j.surfcoat.2007.04.074

[2] Zhao, E.J., Hong, B., Meng, J. and Wu, Z.J. (2009) First Principles Investigation on the Ultra Incompressible and Hard TaN. Journal of Computational Chemistry, 30, 2358-2363. http://dx.doi.org/10.1002/jcc.21234

[3] Tsukimoto, S., Moriyama, M. and Murakami, M. (2004) Microstructure of Amorphous Tantalum Nitride Thin Films. Thin Solid Films, 460, 222-226. http://dx.doi.org/10.1016/j.tsf.2004.01.073

[4] Kim, S.K. and Cha, B.C. (2005) Deposition of Tantalum Nitride Thin Films by DC Magnetron Sputtering. Thin Solid Films, 475, 202-207. http://dx.doi.org/10.1016/j.tsf.2004.08.059

[5] Pilloud, D., Dehlinger, A.S., Pierson, J.F., Roman, A. and Pichon L. (2003) Reactively Sputtered Zirconium Nitride Coatings: Structural, Mechanical, Optical and Electrical Characteristics. Surface and Coatings Technology, 174, 338344. http://dx.doi.org/10.1016/S0257-8972(03)00613-3

[6] Berg, G., Friedrich, C., Broszeit, E. and Berger, C. (1996) Development of Chromium Nitride Coatings Substituting Titanium Nitride. Surface and Coatings Technology, 86, 184-191. http://dx.doi.org/10.1016/S0257-8972(96)03042-3

[7] Vinod, S. (2014) Comprehensive Hard Materials. 1. Newnes.

[8] Lee, H.-K., Lee, H.-Y. and Jeon, J.-M. (2007) Codeposition of Micro- and Nano-Sized SiC Particles in the Nickel Matrix Composite Coatings Obtained by Electroplating. Surface and Coatings Technology, 201, 4711-4717. http://dx.doi.org/10.1016/j.surfcoat.2006.10.004

[9] Yazdani, A., Soltanieh, M., Aghajani, H. and Rastegari, S. (2011) A New Method for Deposition of Nano Sized Titanium Nitride on Steels. Vacuum, 86, 131-139. http://dx.doi.org/10.1016/j.vacuum.2011.04.020

[10] Ali, M., Hamzah, E., Qazi, I. and Toff, M.R.M. (2010) Effect of Cathodic Arc PVD Parameters on Roughness of TiN Coating on Steel Substrate. Cur App Phy, 10, 471-474. http://dx.doi.org/10.1016/j.cap.2009.07.007

[11] Vettivel, S.C., Selvakumar, N. and Leema, N. (2013) Experimental and Prediction of Sintered Cu-W Composite by Using Artificial Neural Networks. Mater. Des., 45, 323-335. http://dx.doi.org/10.1016/j.matdes.2012.08.056

[12] Chang, C.-L., Chen, J.-H., Tsai, P.-C., Ho, W.-Y. and Wang, D.-Y. (2008) Synthesis and Characterization of NanoComposite Ti-Si-N Hard Coating by Filtered Cathodic Arc Deposition. Surf Coat Technol, 203, 619-623. http://dx.doi.org/10.1016/j.surfcoat.2008.04.096

[13] Dinesh Kumar, D., Kumar, N., Kalaiselvam, S., Dash, S. and Jayavel, R. (2015) Micro-Tribo-Mechanical Properties of Nano Crystalline TiN Thin Films for Small Scale Device Applications. Tribology International, 88, 25-30. http://dx.doi.org/10.1016/j.triboint.2015.02.031

[14] Mikulal, P., Vrana, M., Saroun, J., Em, V., Seong, B.S. and Woo, W. (2012) Double Bent Crystal Dispersive Arrangement for High Resolution Diffractometry. J Phy: Conf Ser, 340, 12-14.

[15] Baradeswaran, A., Elayaperumal, A. and Franklin Issac, R. (2013) A Statistical Analysis of Optimization of Wear Behaviour of $\mathrm{Al}-\mathrm{Al}_{2} \mathrm{O}_{3}$ Composites Using Taguchi Technique. Procedia Engineering, 64, 973-982. http://dx.doi.org/10.1016/j.proeng.2013.09.174

[16] Baradeswaran, A., Vettivel, S.C., Elaya Perumal, A., Selvakumar, N. and Franklin Issac, R. (2014) Experimental Investigation on Mechanical Behaviour, Modelling and Optimization of Wear Parameters of B4C and Graphite Reinforced Aluminium Hybrid Composites. Materials \& Design, 63, 620-632. http://dx.doi.org/10.1016/j.matdes.2014.06.054

[17] Saravanan, I., Elaya Perumal, A., Vettivel, S.C., Selvakumar, N. and Baradeswaran, A. (2015) Optimizing Wear Behavior of TiN Coated SS 316L against Ti Alloy Using Response Surface Methodology. Materials and Design, 67, 469482. http://dx.doi.org/10.1016/j.matdes.2014.10.051 